\title{
Diagnostik Kelelahan dengan Sinyal Electrocardiogram (ECG) untuk Kontrol Kecepatan Treadmill Berbasis Fuzzy Logic
}

\author{
Suci Intan Prativy, Siti Halimah Baki, dan Nada Fitrieyatul Hikmah \\ Departemen Teknik Biomedik, Institut Teknologi Sepuluh Nopember (ITS) \\ e-mail: halimah@bme.its.ac.id
}

\begin{abstract}
Abstrak-Electrocardiography (ECG) merupakan alat yang digunakan untuk merekam data aktivitas elektris otot jantung antara lain Heart rate Variability dan durasi sinyal QRS. ECG merupakan indikator yang paling umum digunakan dan dapat menjawab masalah fisiologis manusia dalam keadaan statis dan dinamis, contohnya olahraga. Saat berolahraga ada fase-fase yang harus dilakukan yaitu fase pemanasan, fase proses olahraga itu sendiri, serta fase pendinginan. Namun, sering kali fase-fase ini dilewatkan. Berdasarkan anjuran dari produsen treadmill KETTLER RUN 11 serta dengan bantuan Karvonen Formula dan persen Cardivascular Load (\%CVL), diciptakan sistem untuk menentukan beban latihan saat berolahraga lari berdasarkan kebutuhan tiap-tiap individu. Karvonen Formula merupakan formula yang dipergunakan untuk menghitung nilai heart rate minimal dan maksimal seseorang, dimana dalam perhitungannya dibutuhkan informasi usia, jenis kelamin, nilai resting heart rate, serta level intensitas olahraga yang diinginkan dari individu yang akan dihitung nilai heart rate minimal dan maksimalnya. Parameter \% CVL digunakan untuk mengetahui kapan seseorang harus berhenti berolahraga berdasarkan heart rate maksimal, heart rate minimum dan heart rate saat berolahraga. Pada saat sistem dijalankan, tiga buah elektroda yang terpasang pada dada disambungkan ke ECG untuk kegiatan monitoring. Data yang diambil menunjukan kenaikan heart rate stabil ketika menjalankan fase pemanasan dan fase proses. Sedangkan pada fase pendinginan mengalami penurunan yang juga stabil. Berdasarkan hasil penelitian ini dengan menggunakan 10 subjek, dua diantaranya menghasilkan rata-rata QRS duration sebesar 0,0756 dan 0,025645. Kemudian untuk rata-rata HRV sebesar 190,8990719 dan 250,9516.
\end{abstract}

Kata Kunci-Cardiovascular Load, ECG, Fuzzy, Karvonen Formula, Raspberry Pi

\section{PENDAHULUAN}

$\mathrm{O}$ LAHRAGA merupakan suatu kegiatan yang penting bagi manusia untuk menjaga kondisi tubuh yang sehat. Selain menjaga pola makan yang sehat, olahraga dibutuhkan untuk menjaga metabolisme tubuh. Berbagai macam jenis olahraga banyak digemari manusia. Namun seiring berjalannya waktu, manusia tidak memiliki waktu yang cukup dan ruang gerak yang cukup. Menurut Riskesdas atau Riset Kesehatan Dasar pada tahun 2018, menyebutkan bahwa angka obesitas di Indonesia meningkat hingga mencapai 21,8 persen dan sedikitnya waktu yang dialokasikan untuk berolahraga sehingga memaksimalkan waktu yang ada untuk berolahraga dan mendiforsir tubuh agar dapat dengan cepat menurunkan berat badan [1]. Pada akhirnya, mereka melakukan olahraga didalam ruangan dan seringkali berolahraga secara individual. Kebanyakan masyarakat melakukan olahraga dengan mengabaikan fase-fase penting dalam berolahraga dan memforsir dirinya saat berolahraga dengan memanfaatkan waktu yang sempit. Saat melakukan olahraga ada fase-fase yang harus dilakukan, seperti fase pemanasan, fase olahraga dan fase pendinginan. Fase yang paling sering diabaikan adalah fase pemanasan dan pendinginan [1]. Mereka sering kali langsung melakukan beban olahraga yang berat dan berhenti tanpa ada penurunan berkala. Hal ini dapat membahayakan tubuh, ditambah dengan beban olahraga yang tidak sesuai dengan batas kemampuan tubuh. Electrocardiogram atau ECG, laju pernapasan, dan kadar oksigen dalam darah merupakan beberapa parameter yang dapat mengukur kelelahan tubuh. ECG lebih sering digunakan dalam mengukur kelelahan tubuh terutama saat berolahraga dikarenakan ECG memiliki hubungan linear yang tinggi dengan asupan oksigen dan merupakan indikator yang paling umum digunakan dan dapat menjawab masalah fisiologis manusia dalam keadaan statis dan dinamis [1].

Penelitian pada saat ini untuk mengidentifikasi kelelahan dapat menggunakan suatu rumus bernama Karvonen Formula. Karvonen Formula merupakan formula yang dipergunakan untuk menghitung nilai heart rate minimal dan maksimal seseorang. Dalam perhitungannya dibutuhkan informasi usia, jenis kelamin, nilai resting heart rate, serta level intensitas olahraga yang diinginkan dari individu yang akan dihitung nilai heart rate minimal dan maksimalnya. Namun, Karvonen Formula ini tidak cocok untuk digunakan untuk semua orang [2]. Pada penelitian sebelumnya [2], terdapat subjek yang sudah merasakan kelelahan saat melakukan latihan. dibutuhkan parameter tambahan untuk mendeteksi kelelahan dari individu tersebut. Persen Cardiovascular Load (\%CVL) digunakan untuk mendeteksi kelelahan pada seseorang yang sedang beraktifitas berdasarkan nilai heart rate maksimal. Berdasarkan anjuran dari produsen treadmill KETTLER RUN 11 serta dengan bantuan Karvonen Formula dan \%CVL, dikembangkan suatu sistem untuk menentukan beban latihan saat berolahraga berdasarkan kebutuhan tiap-tiap individu. Penelitian ini menggunakan ECG berbasis ARM yang sudah menggunakan Bluetooth yang kemudian dengan menggunakan Raspberry $P i$ untuk mengontrol kecepatan treadmill KETTLER RUN 11. Hasil penelitian menunjukan kenaikan heart rate stabil ketika menjalankan fase pemanasan dan fase proses. Sedangkan pada fase pendinginan mengalami penurunan yang juga stabil. Detak jantung yang sudah diproses dalam Karvonen Formula dan \%CVL akan menjadi parameter dari Fuzzy Controller yang digunakan sebagai kontroler dalam 


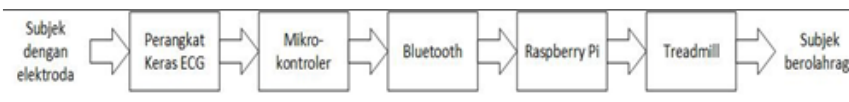

Gambar 1. Diagram Blok Penelitian

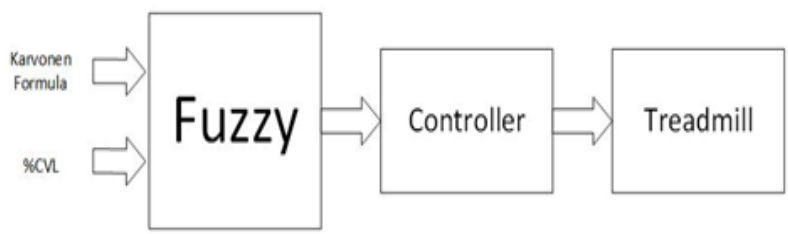

Gambar 2. Diagram blok untuk sistem control

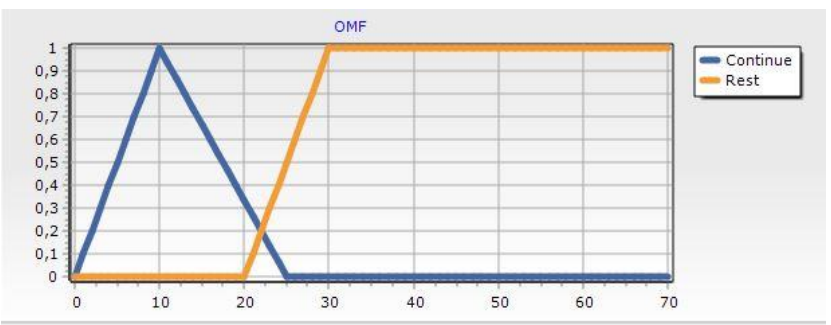

Gambar 3. OMF

sistem ini. Sistem ini merupakan pengembangan dari sistem yang sudah ada dengan menambahakan parameter \%CVL dan Fuzzy Controller.

\section{PERANCANGAN SISTEM}

\section{A. Perancangan Perangkat keras}

Perangkat keras dibagi menjadi dua bagian, yakni perancangan perangkat keras ECG dan mikrokontroler. Keduanya akan dipasangkan pada subjek. Input dari perangkat keras ini adalah sinyal ECG mentah yang didapat dari subjek dengan menggunakan elektroda. Output dari perangkat keras ini adalah sinyal ECG yang sudah difilter. Perancangan perangkat keras ini dapat dilihat pada Gambar 1.

Pada sistem ini digunakan ECG karena instrumentasi dari ECG mudah untuk dibuat, sinyalnya mudah untuk diolah dan banyak fitur yang dapat dianalisa dari ECG tersendiri. Pulse Oximeter adalah alat pengukur detak jantung, namun tidak digunakan dalam penelitian ini dikarenakan kurang akurat dalam perekaman detak jantung dan sistem ini akan menyimpan hasil ECG agar dapat dimonitoring kondisi subjek dengan melihat QRS Duration dan HRV Time Domain pada saat berolahraga.

Filter yang digunakan pada perangkat keras ECG ini adalah $0.05 \mathrm{~Hz}$ dan $40 \mathrm{~Hz}$ dengan penguatan total sebesar 1000 kali, agar sinyal ECG dapat terlihat. Sebelum sinyal diolah oleh Raspberry Pi, pertama-tama ada proses akuisisi data yang harus dilakukan. Data yang diakuisisi adalah data dari perangkat keras ECG ke mikrokontroler STM32F103C8T6. Hal ini dilakukan agar sdata analog yang didapat dari perangkat keras ECG dapat dikonsersi menjadi data digital. Analog to digital converter (ADC) dilakukan agar dapat dilakukan perekaman sinyal jantung dan juga nilai heart rate oleh Raspberry Pi. Proses ini secara penuh dilakukan oleh mikrokontroler STM32F103C8T6. Sehingga untuk perancangan hardware hanya dibutuhkan mikrokontroler STM32F103C8T6 dan satu buah kabel jumper untuk menghubungkan perangkat keras ECG. ADC yang digunakan pada penelitian ini sebesar 16bit dan menggunakan frekuensi sampling sebesar $200 \mathrm{~Hz}$ berdasarkan Teori Pan Tompkin.

Setelah diproses secara analog, sinyal ECG akan diproses secara digital di mikrokontroler, yang mana diproses dengan menggunakan bahasa pemrograman $\mathrm{C}$ dengan menggunakan software Coocox IDE. Kemudian dengan menggunakan Bluetooth HC05 sinyal ECG akan dikirimkan ke minikomputer untuk dilakukan pengolahan sinyal dan kontrol pada treadmill yang diprogram dengan menggunakan bahasa pascal dengan menggunakan software Lazarus. Sinyal analog dikonversi menjadi sinyal digital oleh ADC STM32F103C8T6.

Sistem piranti lunak dimulai dari sampling sinyal dari ECG dengan memanfaatkan analog-to-digital converter yang telah tertanam pada modul STM32F103C8T6. Sinyal keluaran dari ADC akan dikirim secara bluetooth dengan menggunakan modul HC05 pada jarak yang dekat, hal ini untuk mengurangi kabel antara subjek dengan treadmill yang dapat mengganggu kenyamanan subjek dalam melakukan olahraga. Setelah dikirimkan dengan bluetooth, data akan diproses untuk mendapatkan heart rate yang kemudian akan menjadi parameter pendeteksi kelelahan dan kontroller dari treadmill.

\section{B. Perancangan Sistem Kontrol}

Pada tahap ini, terdiri dari proses perhitungan dengan menggunakan Karvonen Formula, \%CVL, Fuzzy dan kontrol Proporsional. Agar lebih jelas dapat dilihat pada Gambar 2. Output dari proses Fuzzy yaitu kecepatan pada treadmill. Kemudian pada rangkaian photocoupler, treadmill akan diatur agar kecepatannya tepat seperti yang diinginkan pada Fuzzy.

\section{Karvonen Formula}

Dalam menggunakan Karvonen Formula, dibutuhkan beberapa data dasar dari tiap-tiap individu. Berikut merupakan langkah-langkah untuk menghitung Heart rate Training Zone menggunakan Karvonen Formula:

1) Hitung nilai resting heart rate (RHR)

2) Hitung estimasi nilai maksimum heart rate (HRMax)ggunakan rumus berikut:

HRMax (laki-laki) $=220-$ usia

HRMax (perempuan $)=226-$ usia

3) Hitung nilai heart rate reserve menggunakan rumus berikut:

HRR = HRMax - RHR

(HRH) dengan

4) Hitung batas bawah dari Heart rate Training Zone (THRMin) dengan menggunakan rumus berikut:

THRMin $=($ HRR $x$ batas intensitas bawah\% $)+$ RHR (4)

5) Hitung batas aras dari Heart rate Training Zone (THRMax) dengan menggunakan rumus berikut:

THRMax $=($ HRR $x$ batas intensitas atas\% $)+$ RHR

Karvonen formula ini akan menjadi input membership function (IMF) pada fuzzy. Setiap zona olahraga akan memliki aturan IMF nya tersendiri, menggambarkan bahwa subjek yang termasuk zona beginner, akan masih dapat berolahraga saat subjek masih termasuk pada batas THRmin dan THRmax, diluar dari batas tersebut subjek sudah dapat dinyatakan bahwa tidak dapat melanjutkan berolahraga sehingga sistem akan tidak melanjutkan protokol olahraga yang sudah disediakan melainkan akan langsung memasuki fase pendinginan. Hal ini juga berlaku pada zona average dan advance. 
Tabel 1.

ATURAN FUZZY LOGIC

\begin{tabular}{ccc}
\hline \hline & THRMAX & THRmax \\
\hline jalan & Beg/Ave/Adv & Tired \\
lari & lanjut & berhenti \\
stop & lanjut & berhenti \\
& berhenti & berhenti \\
& THRmin & THRmax \\
jalan & Beg/Ave/Adv & Tired \\
lari & lanjut & berhenti \\
stop & lanjut & berhenti \\
\hline \hline
\end{tabular}

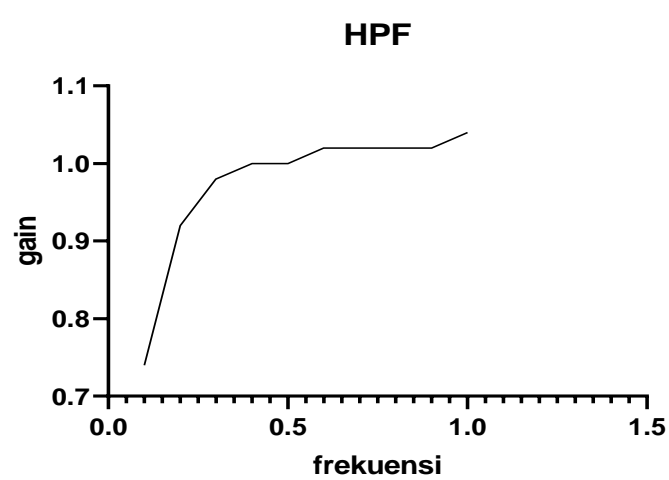

Gambar 5. Respon Frekuensi High Pass Filter

\section{D. $\% C V L$}

Parameter \%CVL ini melengkapi parameter Karvonen Formula. Penentuan klasifikasi kondisi kesehatan berdasarkan indikator denyut nadi kerja yang dibandingkan dengan denyut nadi maksimum karena persentase Cardiovascular Load (\% CVL), dapat dihitung dengan

$\% C V L=100 x \frac{\text { (Denyut nadi kerja-Denyut nadi Istirahat })}{(\text { Denyut Nadi maksimum-Denyut nadi istirahat })}$

dimana denyut nadi istirahat adalah rata-rata denyut nadi sebelum bekerja, denyut nadi kerja adalah rata-rata denyut nadi selama bekerja dan denyut nadi maksimum adalah 220 dikurang umur (untuk pekerja laki-laki).

Parameter \%CVL akan menjadi input membership fucntion (IMF) pada fuzzy. Penggolongan IMF pada \%CVL ini hanya digolongkan menjadi tiga bagian saja yaitu low, medium dan high.

\section{E. Kontrol Fuzzy}

Kontrol Fuzzy ini digunakan untuk mengkontrol kecepatan pada treadmill. Input dari kontrol fuzzy adalah heartrate yang didapatkan secara realtime yang kemudian diubah menjadi IMF dengan menggunakna Karvonen Formula dan \%CVL, dan outputnya berupa sinyal kontrol kecepatan treadmill yang akan dikalikan dengan gain yang proporsional untuk mengontrol kecepatan tertentu yang sesuai untuk menjadi input dari plant yaitu treadmill.

Sebelum melakukan olahraga, subjek akan memilih intensitas olahraga subjek berdasarkan Heart rate Training Zone subjek yang akan mempengaruhi perhitungan dari Karvonen Formula. IMF dari Karvonen Formula dibuat berdasarkan Kategori Laki-laki dengan rentang usia 18 hingga 25 tahun. IMF dari \%CVL dibuat IMF dikatakan Low saat klasifikasi \%CVL dengan rentang 0 hingga 30\%, untuk dikatakan Normal saat 30 hingga $80 \%$ dan untuk dikatan High saat 80 hingga $100 \%$. Fuzzy rule dibuat berdasarkan heartrate realtime yang diolah menjadi \%CVL dan Karvonen Formula menentukan kondisi tubuh yang nantinya

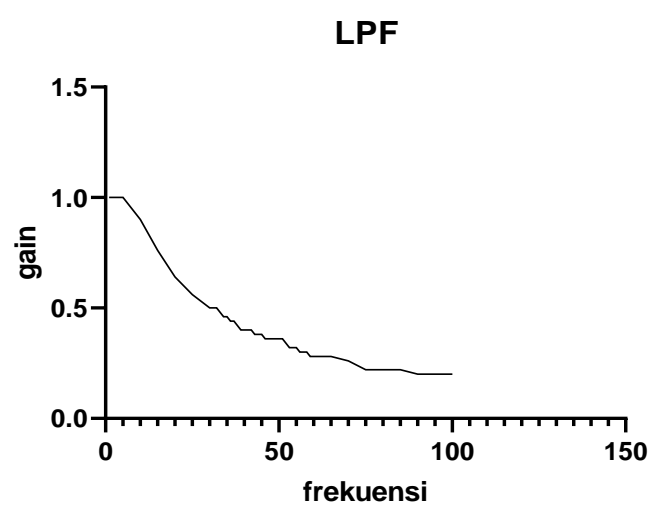

Gambar 4. Respon Frekuensi Low Pass Filter

menentukan kecepatan treadmill yang seharusnya. Aturan pada fuzzy logic ini dapat dilihat pada Tabel 1 yang berdasarkan dari IMF yang kemudian menghasilkan grafik output membership function (OMF) seperti pada Gambar 3. Defuzzifikasi yang digunakan untuk menghasilkan OMF digunakan metode Centroid Method atau dapat disebut juga sebagai Center of Area. Metode ini digunakan karena mudah untuk diaplikasikan dengan peraturan Fuzzy Logic apapun dan cukup akurat.

Hubungan yang digunakan untuk kedua input tersebut yaitu and logic. Jika Karvonen Formula mengindikasi dapat terus berolahraga dan \%CVL juga memberikan indikasi yang sama, maka OMF yang akan dihasilkan yaitu "Continue". Namun, saat salah satu dari parameter tersebut mengindikasi harus berhenti, maka OMF yang akan dihasilkan yaitu "Rest". Saat OMF yang didapatkan berupa "Continue", maka proses olahraga ini akan terus berlanjut sesuai dengan kecepatan yang seharusnya sesuai dengan protokol olahraga yang sudah disediakan. Saat OMF yang didapat berupa "Rest", maka proses olahraga ini akan berhenti atau kecepatan treadmill ini akan berkurang sesuai dengan kecepatan treadmill saat fase pendinginan.

\section{HASIL DAN ANALISA}

\section{A. Perangkat keras}

Pengujain rangaian dilakukan dengan memasukan sinyal input sinusoidal dari function generator dengan amplitudo tertentu. Kemudian sinyal dikuatkan amplitudonya dengan rangkaian instrumentasi amplifier sehingga diperoleh nilai amplitudo yang merupakan hasil perkalian gain dengan amplitudo sinyal sinusoidal yang menjadi input rangkaian. Sinyal input dari function generator merupakan sinyal dengan frekuensi $20 \mathrm{~Hz}$ dengan amplitudo $0.1 \mathrm{~V}$. Sinyal diuji dengan dimasukan ke input positif sedangkan pada input negatif dihubungkan ke ground sehingga bernilai 0V. Resistor variable yag merupakan pengarur besar dari gain ditetapkan pada nilai $500 \Omega$ dan didapatkan nilai penguatan sebesar 100 kali.

Pengujian dilakukan dengan dua tahap untuk mengecek rangkaia High Pass Filter dan Low Pass filter. Pengujian pada rangkaian High Pass Filter dilakukan dengan memberikan sinyal masukan sinus dari rentang $0,1 \mathrm{~Hz}$ hingga $1 \mathrm{~Hz}$. Pengujian rangkaian Low Pass Filter dilakukan dengan memberikan sinyal input sinus dengan rentang frekuensi $1 \mathrm{~Hz}$ hingga $100 \mathrm{~Hz}$. Pengujian rangkaian dilakukan dengan 
memberikan input sinyal yang bervariasi dengan function generator dengan berbagai macam frekuensi dengan melihat outputnya yang memiliki hasil yang sama persis dengan inputnya. Sinyal input dengna frekuensi $20 \mathrm{~Hz}$ dengan amplitudo $1 \mathrm{~V}$. Pengujian rangkaian dilakukan dengan memberikan input sinyal yang bervariasi dari function generator dengan berbagai macam frekuensi dan dilihat kenaikan tegangannya. Tegangan offset diatur dengan memutar resistor variable multiturn.

Pada rangkaian High Pass Filter dengan rancangan cut-off $0.05 \mathrm{~Hz}$, secara ideal penguatan ketika pada frekuensi 0.05 $\mathrm{Hz}$ adalah 0.707 dan sebelum frekuensi $0.05 \mathrm{~Hz}$ sinyal akan teredam. Namunm berdasarkan hasil pengujian yang dilakukan, penguatan 0.707 didapatkan pada zona frekuensi kisaran $0.06 \mathrm{~Hz}$, seperti pada Gambar 5. Penguatan maksimal frekuensi dibawah cut-off adalah 1,04. Kesalahan frekuensi cut-off adalah $0.06 \mathrm{HZ}-0.05 \mathrm{~Hz}=0.01 \mathrm{~Hz}$, namun masih dapat ditoleransi karena sinyal yang dibutuhkan berada pada frekuensi 6-15 Hz.

Pada rangkaian Low pass filter dengan rancangan cut-off $40 \mathrm{~Hz}$ dan penguatan 1x, secara ideal penguatan ketika pada frekuensi $40 \mathrm{~Hz}$ adalah 7.07 dan setelah frekuensi $40 \mathrm{~Hz}$ sinyal akan teredam. Namun berdasarkan hasil pengujian yang dilakukan, penguatan 7.07 didapatkan pada zona frekuensi kisaran $15 \mathrm{~Hz}$, seperti pada Gambar 4. Penguatan maksimal frekuensi dibawah cut-off adalah 0,2. Kesalahan frekuensi cut-off adalah $40 \mathrm{~Hz}-15 \mathrm{~Hz}=25 \mathrm{~Hz}$, namun masih dapat ditoleransi karena sinyal yang dibutuhkan berada pada frekuensi 6-15 Hz.

Pada perangkat keras ECG didapatkan sinyal ECG yang terlah terfilter. Sinyal ECG tersebut sudah dilakukan pengamatan dengan menggunakan Osiloskop, pengiriman data serial dengan menggunakan arduino, dan penerimaan data serial pada raspberry pi dengan menggunakan program lazarus dan python. Sinyal yang didapat masih memiliki noise yang disebabkan oleh interferensi listrik oleh lingkungan sekitar pengambilan data meskipun rangkaian ECG ini telah dilengkapi oleh notch filter sebesar $50 \mathrm{~Hz}$.

\section{B. Perangkat Lunak}

Pengujian perangkat lunak yang terdapat pada raspberry yang digunakan untuk menentukan apakah subjek lelah atau tidak. Pada pengujian digunakan data ecg pada orang yang diam, kemudian ditentukan kondisi subjek.

Selain terdapat program fuzzy untuk mendiagnostik kelelahan dari subjek, program ini terdapat program tambahan yaitu QRS duration dan HRV time domain, sdengan menggunakan data ECG yang memilik heartrate sebesar 86 bpm masih tergolong dapat melanjutkan olahraga. Dengan perhitungan dengan menggunakan Karvonen Formula dengan intensitas olahraga beginner dan berumur 22 tahun, THRmax dan THRmin masih masuk ke dalam batas beginner dan \%CVL masih tergolong dalam kondisi berlari. Sehingga setelah memasuki logika fuzzy, hasilnya subjek masih dapat melanjutkan olahraga. Selain itu pada Gambar 6 dapat dilihat grafik QRS duration dan HRV time domain.

Pengujian keseluruhan system dilakukan dengan menggunakan subjek normal sehat yang masuk pada katagori usia 18-25 tahun dengan berbagai intensitas olahraga yang berjumlah 10 subjek, dengan jenis kelamin perempuan dan laki-laki. Sebelum dilakukan pengujian pada subjek, perlu
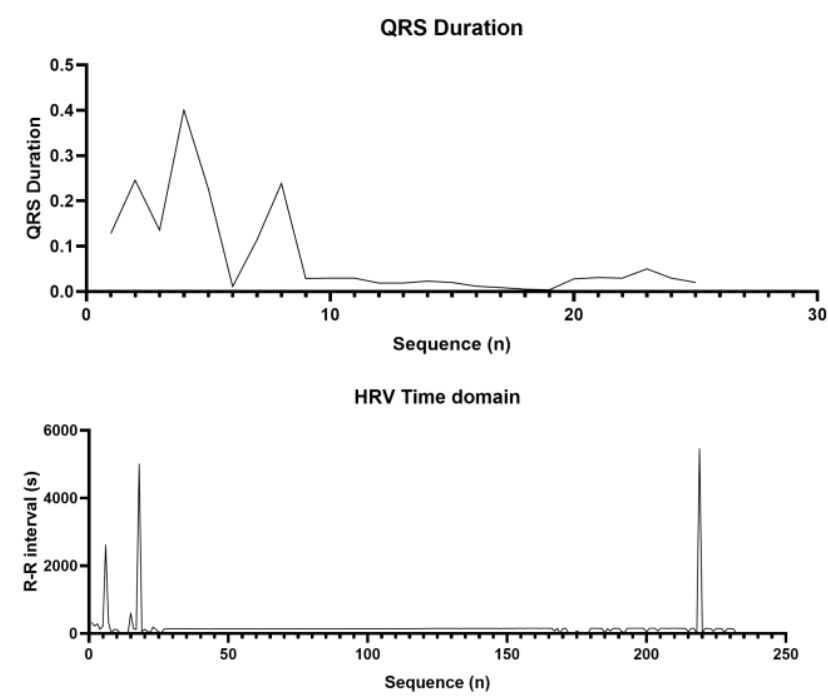

Gambar 6. Hasil QRS duration dan R-R Tachogram dari subjek

Heart Rate

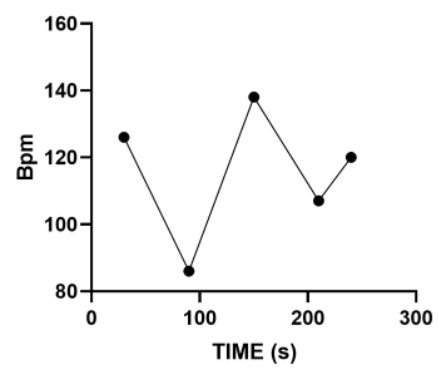

Gambar 7. Grafik heart rate pada setiap fase olehraga

dilakukan proses instalasi elektroda pada dada subjek dengan konfigurasi einthoven. Sumber tegangan yang digunakan untuk raspberry menggunakan sumber tegangan listrik biasa dan untuk perangkat keras ECG menggunakan baterai delapan buah yang memiliki spesifikasi 3.7-4.2 $\mathrm{V}$ dengan kapasitas 99000mAh. Baterai tersebut akan dibagi menjadi dua menjadi sumber $\pm 16 \mathrm{~V}$ yang nantinya akan melewati regulator sehingga sumber yang masuk ke setiap rangkaian sebesar $\pm 12 \mathrm{~V}$.

Proses pengujian keseluruhan system pada subjek dimulai dengan subjek diminta untuk memasangkan elektroda sesuai instruksi kemudian subjek akan berdiri pada treadmill yang terdapat layar lcd touchscreen yang menampilkan interface dari program. Sebelum program dimulai, subjek diminta untuk menuliskan nama, umur, jenis kelamin dan tingkat intensitas olahraga subjek. Kemudian subjek akan dimulai perhitungan heart rate saat subjek dalam kondisi sebelum olahraga. Setelah mendapatkan heart rate sebelum berolahraga, subjek akan memencet tombol start yang menandakan sistem akan berjalan. Data yang akan diambil pada keseluruhan sistem ini berupa sinyal mentah ECG, heart rate pada waktu tertentu, $Q R S$ duration dan HRV dari subjek selama system berjalan.

Penggunaan elektroda disamping puting saat keadaan subjek sedang diam, gelombang QRS cenderung baik namun dapat dilihat pada Gambar 7 terdapat banyak noise dikarenakan disamping puting lebih dekat dengan otot pada tangan yang sering kali bergerak bersamaan dengan bergeraknya kaki. Pada Gambar 7 juga dapat dilihat bahwa saat pemanasan jarak R-R interval normal, kemudian saat mulai mempercepat kecepatan seperti berjalan cepat, R-R 


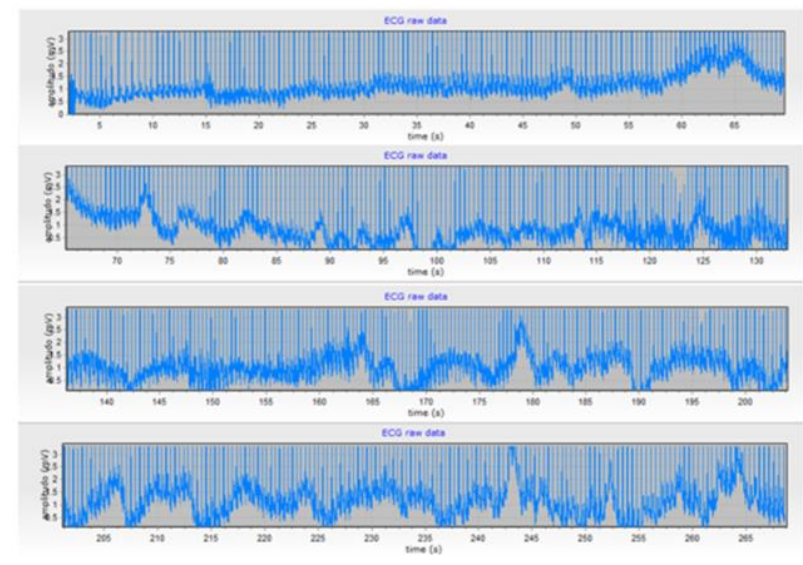

Gambar 8. Hasil ECG dari subjek 1

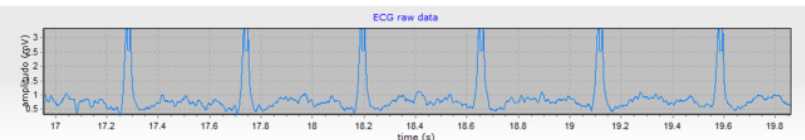

Gambar 9. ECG pada gelombang QRS saat pemanasan pada subjek 1

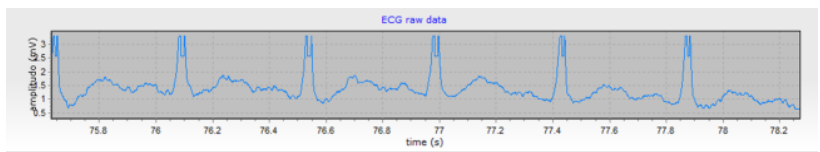

Gambar 10. ECG pada gelombang QRS saat jalan cepat pada subjek 1

interval terlihat memendek hingga saat berlari R-R interval menjadi sangat pendek. Pada Gambar 8 dapat dilihat perubahan dari heart rate subjek 1 saat berolahraga. Dibandingkan dengan teori yang ada, grafik tersebut kurang sesuai karena terdapat noise yang disebabkan oleh pergerakan subjek dan penempatan dari elektroda. Pada Gambar 9 yaitu kondisi saat pemanasan, terlihat jelas gelombang $\mathrm{R}$, jarak antara gelombang $\mathrm{R}$ yaitu \pm 0.4 detik. Pada Gambar 10, gelombang $\mathrm{R}$ tetap terlihat dan gelombang $\mathrm{T}$ lebih terlihat dibandingkan pada saat pemanasan. Pada Gambar 11, jarak antara gelombang $\mathrm{R}$ lebih dekat yaitu \pm 0.3 detik karena tubuh memerlukan pendistribusian darah dengan kandungan oksigen lebih tinggi. Gambar 12, jarak antara gelombang R masih cenderung pendek seperti pada saat kondisi lari namun sudah mulai memanjang. Gambar 13 gelombang QRS mulai normal kembali dengan jarak antara gelombang $\mathrm{R} \pm 0.4$ detik. Pada Gambar 6 didapatkan hasil QRS Duration dari subjek 1 yang menandakan tidak ada perubahan signifikan dari proses olahraga dan HRV dari subjek 1 yang seharusnya meningkat

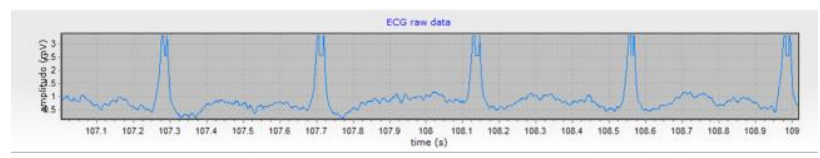

Gambar 11. ECG pada gelombang QRS saat lari pada subjek 1

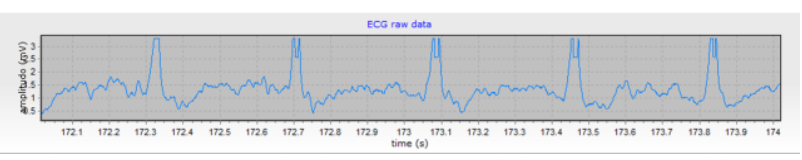

Gambar 12. ECG pada gelombang QRS saat jalan cepat pada subjek 1

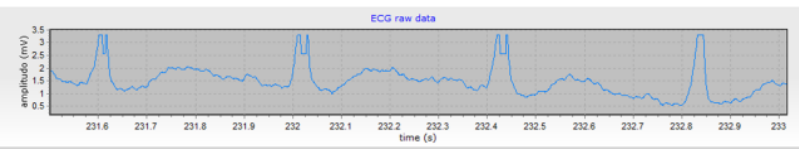

Gambar 13. ECG pada gelombang QRS saat pendinginan pada subjek 1

saat heartrate subjek bertambah.

\section{KESIMPULAN}

Berdasarkan perancangan, pengujian dan analisa sistem yang telah dilakukan, dapat ditarik beberapa kesimpulan dari tugas akhir ini adalah untuk melihat gelombang ECG dari subjek, dibutuhkan untuk melewati rangkaian instrumentasi amplifier, filter dengan cut-off $0.05 \mathrm{~Hz}$ dan $40 \mathrm{~Hz}$, rangkaian Isolation dan Adder. QRS Duration saat sebelum berolahraga, berolahraga dan pasca berolahraga memiliki perubahan yang tidak signifikan, dan Karvonen Formula dan \%CVL dapat digabungkan dengan Fuzzy untuk mendiagnosis kelelahan berdasarkan ECG subjek. Dari penelitian ini dengan menggunakan 10 subjek, dua diantaranya menghasilkan ratarata QRS duration sebesar 0,0756 dan 0,025645. Kemudian untuk rata-rata HRV 190,8990719 dan 250,9516.

Setelah melakukan penelitian ini pada penelitian berikutnya diharapkan perangkat keras dari ECG lebih kecil agar lebih portable. Diharapkan menambah parameter yang lebih detail lagi untuk mendiagnotik kelelahan seseorang saat berolahraga.

\section{DAFTAR PUSTAKA}

[1] L. A. R. Winanda, T. W. Adi, and N. Anwar, "Model prediksi kelelahan pekerja konstruksi di lokasi proyek," J JITS Udayana, 2017.

[2] Mufiedah, "Kontrol Kecepatan dan Inklinasi Pada Treadmill Berdasarkan Data Kardiovaskular,” Surabaya, 2016. 